\title{
Prostate Carcinoma Metastatic in the
} Bone

National Cancer Institute

\section{Source}

National Cancer Institute. Prostate Carcinoma Metastatic in the Bone. NCI Thesaurus.

Code C36308.

A carcinoma that arises from the prostate gland and has spread to the bone. 